SANDIA REPORT

SAND93-1076 - UC-1006

Unlimited Release

Printed November 1993

\title{
Standard Testing Procedures for Optical Fiber and Unshielded Twisted Pair at Sandia National Laboratories
}

R. L. Adams

Prepared by Sandl National Luberriovise

Albuquerque, Now Mexloo 87185 and Uvermore, Calliomia 94550 for the United Statee Department of Energy

under Contract DE-ACoA-9AALS5000 
Issued by Sandia National Laboratories, operated for the United States Department of Energy by Sandia Corporation.

NOTICE: This report was prepared as an account of work sponsored by an agency of the United States Government. Neither the United States Government nor any agency thereof, nor any of their employees, nor any of their contractors, subcontractors, or their employees, makes any warranty, express or implied, or assumes any legal liability or responsibility for the accuracy, completeness, or usefulness of any information, apparatus, product, or process disclosed, or represents that its use would not infringe privately owned rights. Reference herein to any specific commercial product, process, or service by trade name, trademark, manufacturer, or otherwise, does not necessarily constitute or imply its endorsement, recommendation, or favoring by the United States

Government, any agency thereof or any of their contractors or subcontractors. The views and opinions expressed herein do not necessarily state or reflect those of the United States Government, any agency thereof or any of their contractors.

Printed in the United States of America. This report has been reproduced directly from the best available copy.

Available to DOE and DOE contractors from Office of Scientific and Technical Information

PO Box 62

Oak Ridge, TN 37831

Prices available from (615) 576-8401, FTS 626-8401

Available to the public from

National Technical Information Service

US Department of Commerce

5285 Port Royal Rd

Springfield, VA 22161

NTIS price codes

Printed copy: A03

Microfiche copy: A01 
SAND93-1076

Unlimited Release

Distribution

Printed November 1993

\title{
Standard Testing Procedures for Optical Fiber and Unshielded Twisted Pair at Sandia National Laboratories
}

\author{
R. L. Adams \\ Communications Department \\ Sandia National Laboratories \\ Albuquerque, NM 87185-5800
}

\begin{abstract}
This document will establish a working standard for testing optical fiber and unshielded twisted pair cables included in the Lab-wide telecommunications cabling system. The purpose of these standard testing procedures is to deliver to all Sandians a reliable, low-maintenance, state-of-the-art, ubiquitous telecommunications cabling infrastructure capable of satisfying all current and future telecommunication needs.
\end{abstract}




\section{Acknowledgment}

I would like to thank Jon A. Eberhart of Holmes and Narver Inc. His assistance in formalizing the information contained in this document, especially in the Unshielded Twisted Pair section, was greatly appreciated.

I would like to thank Bob Hoagland of Wavetek for offering his pioneering work in EUTP testing documentation. 


\section{Preface}

Since the early 1980s, the Communications Department has been installing optical fiber and unshielded twisted pair cables as part of the Secure data communications network. Recently, a major building recabling project was initiated at Sandia National Laboratories, New Mexico. This project consists of massive intra-building cable installations containing optical fiber and unshielded twisted pair cables. This project was the impetus for creating this testing procedures document.

This document defines standard testing procedures for optical fibers (both Multimode and Single Mode) and extended frequency unshielded twisted pairs. Adherence to these testing procedures will ensure the highest quality end-to-end transmission capability standard throughout Sandia's entire telecommunications infrastructure.

This document assumes manufacturer-recommended, hardware-specific installation and termination procedures have been implemented on associated components. The termination procedures included in this document incorporate some Sandia-specific modifications. Most of these modifications are products of several years of field installation experience. They have yielded superior end-to-end communications performance. Creating this high-quality standard telecommunications cabling infrastructure will greatly contribute to Sandia's ability to remain one of the premiere high technology research and development centers in the world 


\section{Contents}

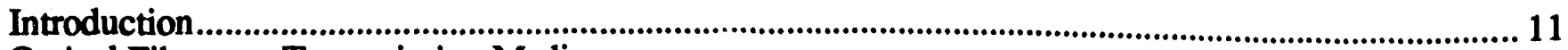

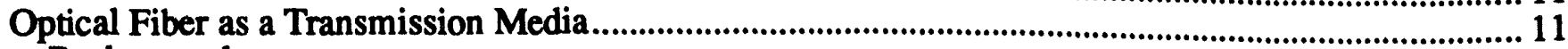

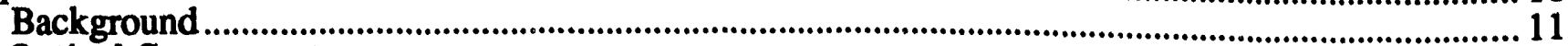

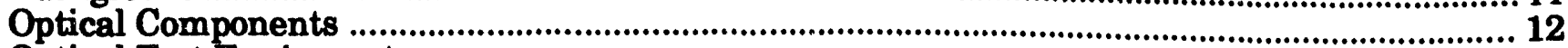

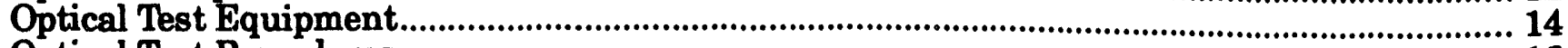

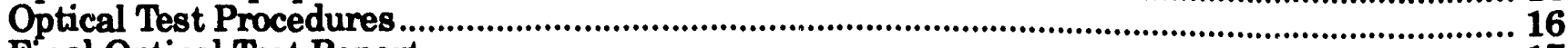

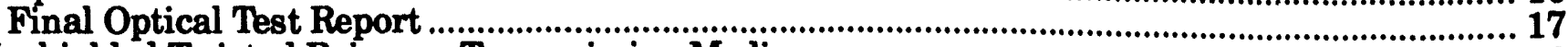

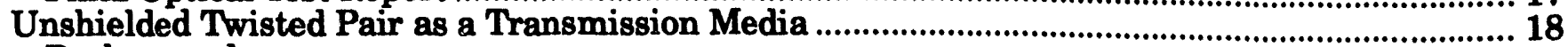

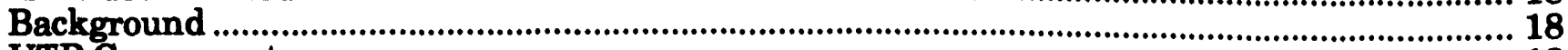

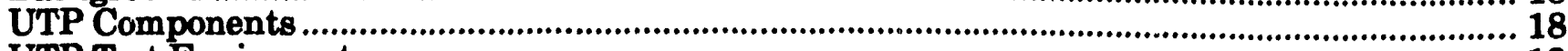

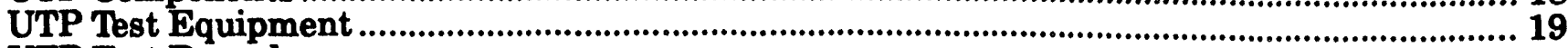

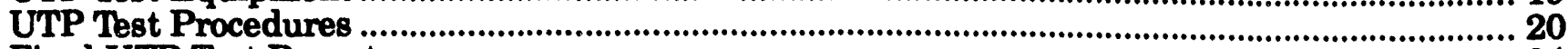

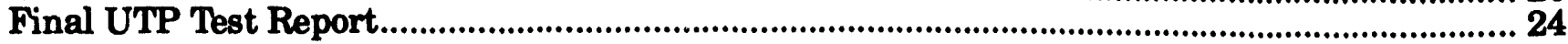

\section{Figures}

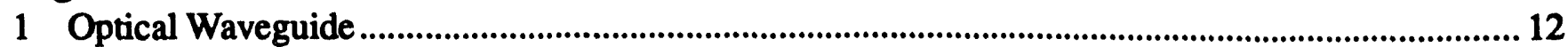

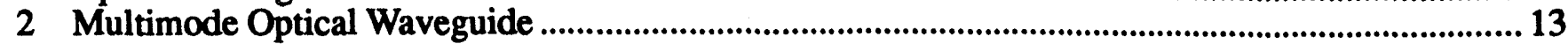

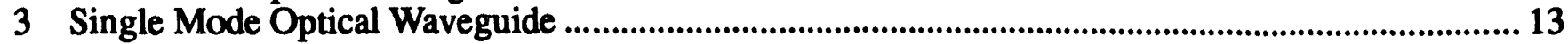

\section{Tables}

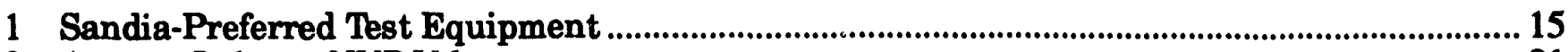

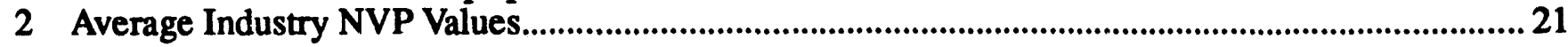

\section{Forms}

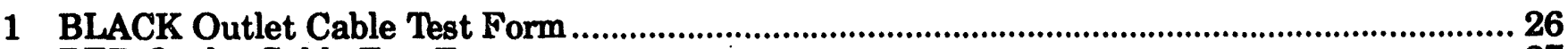

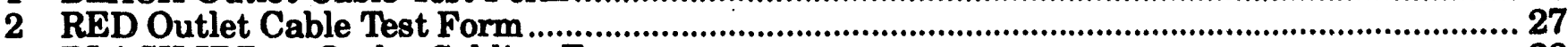

3 BLACK IDR-to-Outlet Cabling Form ....................................................................................... 28

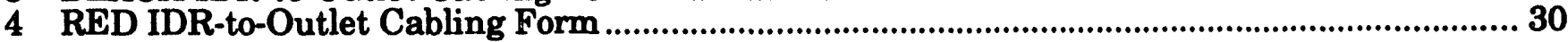




\section{Acronyms}

\begin{tabular}{|c|c|}
\hline $\begin{array}{l}\text { 10BaseF } \\
\text { 10BaseT }\end{array}$ & $\begin{array}{l}10 \text { Mbps baseband optical fiber media } \\
10 \text { Mbps baseband twisted pair media }\end{array}$ \\
\hline $\mathrm{AC}$ & alternating current \\
\hline ANSI & American National Standards Institute \\
\hline ATM & asynchronous transfer mode \\
\hline AT\&T & American Telephone and Telegraph \\
\hline AWG & American wire gauge \\
\hline dB & decibel \\
\hline $\mathrm{dBm}$ & decibels referenced to a milliwatt \\
\hline$\overline{\mathrm{CaA}}$ & cable attenuation in $\mathrm{dB} / \mathrm{km}$ \\
\hline $\mathrm{CaL}$ & cable length in kilometers \\
\hline CoA & connector attenuation in $\mathrm{dB}$ \\
\hline CoQ & connector quantity \\
\hline CSMA/CD & carrier sense multiple access/collision detection \\
\hline DC & direct current \\
\hline DOE & Department of Energy \\
\hline EIA/TIA & Electronic Industries Association/Telecommunications Industry Association \\
\hline EMF & electromagnetic fields \\
\hline EMI & electromagnetic interference \\
\hline EUTP & enhanced unshielded twisted pair \\
\hline FDDI & fiber distributed data interface \\
\hline $\mathrm{ft}$ & feet \\
\hline Gbps & gigabps, one billion bits per second \\
\hline GHz & gigahertz, one billion cycles per second \\
\hline HIGH-5 & $\begin{array}{l}\text { AT\&T product designation for hardware capable of transmission rates up to } \\
155 \mathrm{Mbps}\end{array}$ \\
\hline $\mathbf{H z}$ & Hertz, frequency in cycles per second \\
\hline IBM & International Business Machines \\
\hline IDR & intermediate distribution room \\
\hline IEEE & Institute of Electrical and Electronics Engineers \\
\hline $\mathbf{K H z}$ & kilohertz, one thousand cycles per second \\
\hline Km & kilometer, one thousand meters \\
\hline LAN & local area network \\
\hline LED & light-emitting diode \\
\hline Mbps & megabps, one million bits per second \\
\hline MHz & megahertz, one million cycles per second \\
\hline micron & one millionth of an inch \\
\hline MM & multimode (optical fiber) \\
\hline $\mathbf{m V}$ & millivolts, one thousandth of a volt \\
\hline $\mathbf{m W}$ & milliwatt, one thousandth of a Watt \\
\hline NEXT & near-end cross-talk \\
\hline nm & nanometer, one millionth of a meter \\
\hline NVP & nominal velocity of propagation \\
\hline OF & optical fiber \\
\hline OLTS & optical loss test set \\
\hline ORL & optical return loss \\
\hline OTDR & optical time domain reflectometer \\
\hline PBX & private branch (or business) exchange \\
\hline
\end{tabular}




$\begin{array}{ll}\text { POF } & \text { plastic optical fiber } \\ \text { pf } & \text { picofarad, one trillionth of a farad (capacitance) } \\ \text { PTA } & \text { predicted total attenuation for optical fibers } \\ \text { RFI } & \text { radio frequency interference } \\ \text { RJ } & \text { registered jack } \\ \text { RMS } & \text { root mean square } \\ \text { SM } & \text { single mode (optical fiber) } \\ \text { SNL } & \text { Sandia National Laboratories } \\ \text { SNL/NM } & \text { Sandia National Laboratories/New Mexico } \\ \text { SOF } & \text { silicon optical fiber } \\ \text { SONET } & \text { synchronous optical network } \\ \text { ST } & \text { straight tip (optical connector) } \\ \text { STII } & \text { straight tip version 2 (optical connector) } \\ \text { TDR } & \text { time domain reflectometer } \\ \text { THz } & \text { terahertz, one trillion cycles per second } \\ \text { TSB } & \text { technical systems bulletin } \\ \text { TV } & \text { television } \\ \text { UL } & \text { Underwriter's Laboratories } \\ \text { USOC } & \text { Universal Service Order Code } \\ \text { UTP } & \text { unshielded twisted pair } \\ \text { VOM } & \text { volt-ohm-milliammeter }\end{array}$




\section{Standard Testing Procedures for Optical Fiber and Unshielded Twisted Pair at Sandia National Laboratories}

\section{Introduction}

Past telecommunications cabling distribution systems at Sandia National Laboratories were designed and installed to meet simple transmission requirements. Voice and data transmissions typically required frequencies in the low KiloHertz (KHz) range. Today's technologies are requiring frequencies in the MegaHertz $(\mathrm{MHz})$ range and rapidly approaching the GigaHertz (GHz) range. New cable infrastructures must be installed to meet these expanding bit-rate demands.

The capabilities of a modern cable infrastructure are primarily dependant on component quality and termination procedures. Components include cables, connectors, and couplers. Sandia's high-quality components are identified in SAND93-0002, Intra-Building Telecommunications Cabling Standards for Sandia National Laboratories, New Mexico. Maximum performance of these components can only be realized by proper installation and termination procedures. When installed and assembled, the components function as a single integrated unit or communications path.

All cable installation at Sandia will follow manufacturer-recommended installation procedures. Improper cable installation can drastically degrade the cable infrastructure capabilities by adding random inconsistencies, primarily frequency/bandwidth variations. All AT\&T cable installations at Sandia will follow procedures described in AT\&Ts SYSTIMAX Premises Distribution System Installation Guidelines document.
All cable termination at Sandia will follow manufacturer-recommended termination procedures. Cable termination requires many sophisticated mechanical assembly techniques and the use of high-precision tools and test equipment. As with improper installation, improper termination techniques can also drastically degrade the cable infrastructure capabilities. For example, improper terminations can result in unacceptable attenuation and back reflections. The investment in high-quality components would be lost if termination procedures were not performed in a standard repeated method!

It is therefore absolutely necessary to adhere to the specific test procedures as defined in this document to assure ubiquitous capability, compatibility, expandability, reliability, and functionality throughout the Lab-wide telecommunications cabling infrastructure.

\section{Optical Fiber as a Transmission Media}

\section{Background}

In the past 20 years, a tremendous amount of research and design effort has been directed toward developing lightwave transmission. Lightwave transmission is based upon the physical principle of total internal reflection of light. A principle component of lightwave transmission is the actual lightguide, commonly referred to as an "optical fiber." Today's popular uses of optical fiber as a transmission media include voice, data, and video applications. Optical fibers offer many communication advantages such as: immunity 
to external ElectroMagnetic Fields (EMF), minimization of signal coupling between adjacent conductors, the capability of withstanding caustic atmospheric environments, and most importantly, the propagation of very high bit-rate transmissions across long distances.

\section{Optical Components}

Optical components utilized at Sandia include optical fibers, connectors, couplers, termination panels, and splices. Specific optical components to be used at SNL/NM are listed in SANDS3-0002. The following is a general description of each component.

\section{Optical Fibers}

An optical fiber is a cylindrically shaped light waveguide. Today, high bit-rate transmission optical fibers are typically made of doped silicon and sometimes referred to as Silicon Optical Fibers (SOFs). Plastic Optical Fibers (POFs) are currently being researched for high bit-rate applications; however, excessive internal optical attenuation has limited their deployment. Optical fibers are typically internally structured in two concentric regions, the core and the cladding. (See Figure 1.) The core material, having a slightly higher index of refraction than the cladding material, channels the light by the principle of total internal reflection. Total internal reflection is a physical phenomenon which occurs when light rays in the core region strike the core/cladding interface at less than the critical angle. These rays continue this reflection phenomenon and propagate the fiber.

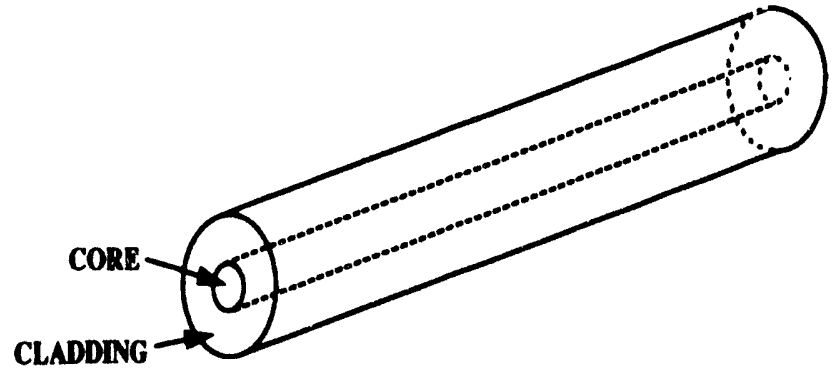

Fgure 1. Optical Waveguide (commonly referred to as an optical fiber)
Optical fibers have evolved into two basic types, Multimode and Single Mode. These types of optical fibers have been incorporated within many national standards such as 10BaseF and FDDI. Newly developing standards such as Fiber Channel, SONET and ATM will also incorporate them.

Multimode fiber is manufactured to accept and propagate multiple modes (up to 1,000) or many light paths concurrently through the core material. (See Figure 2.) Mode propagation depends on physical parameters of the core such as 1) diameter, 2) numerical aperture, and 3) the injected light wave-length. Slight variations in propagation time of different modes of injected light result in "pulse spreading." As the frequency of light/no-light (representing digital ones and zeroes) increases, the length of the optical fiber must be decreased. The bandwidth of Multimode fiber is typically expressed as cycles per second for a given distance. Multimode fiber specified at Sandia is capable of at least 500 $\mathrm{MHz} / \mathrm{Km}$ and has a core diameter of $62.5 \mathrm{mi}$ crons with a cladding diameter of 125 microns. The ideal injected light wavelengths are 850 and 1300 nanometers ( $\mathrm{nm}$ ). These wavelengths correspond to low loss windows present in Multimode fiber.

Single Mode fiber is manufactured to theoretically accept and propagate a single mode (the axial mode) of light through the core material. (See Figure 3.) With one mode of light, there is virtually no "pulse spreading." This physical design parameter translates into extremely high bandwidth capability in the TeraHz range. The core diameter of Single Mode fiber specified at Sandia is $\mathbf{8 . 3}$ microns with a cladding diameter of 125 microns. Light propagating through a Single Mode fiber actually travels in a "mode field" which is slightly larger in diameter than the core. The mode field has an approximate diameter of 8.7 microns. This is a critical parameter if optimal connections are desired between two fibers. The ideal injected light wavelengths for Single Mode fiber are 1310 and 1550 nanometers. These wavelengths correspond to low loss windows present in Single Mode fiber. 


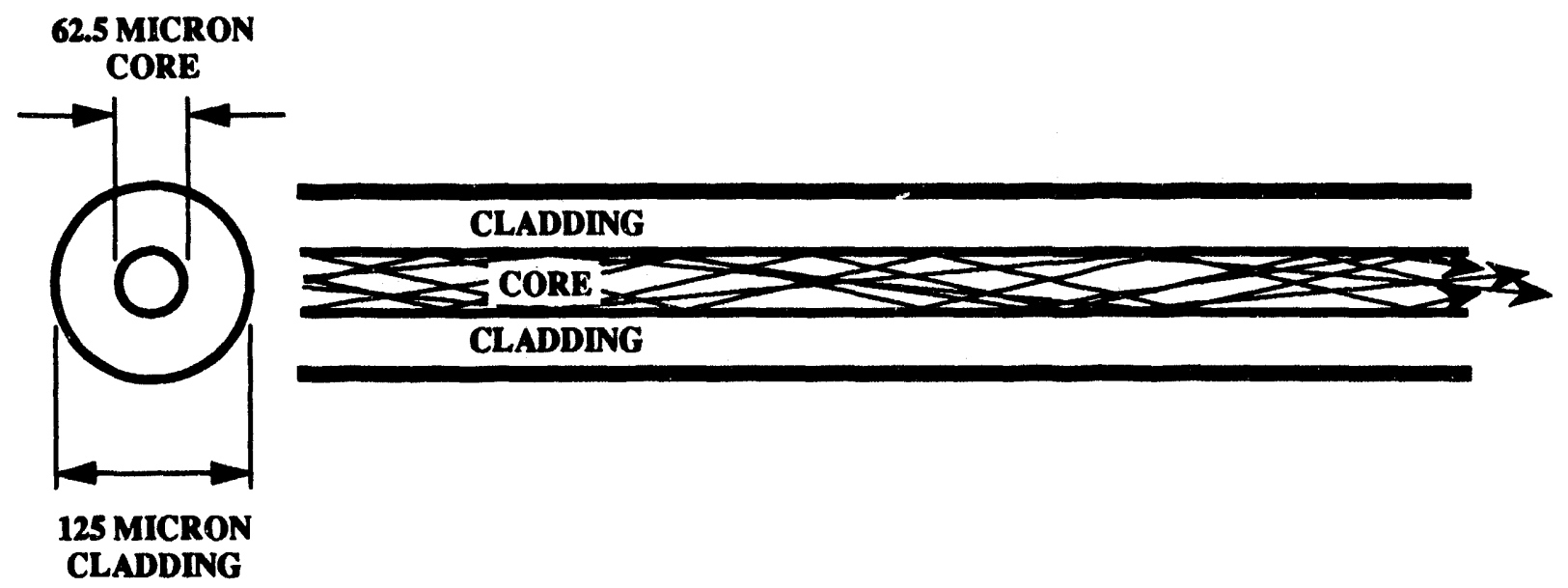

Flgure 2. Multimode Optical Waveguide (allows many paths of light to propagate)
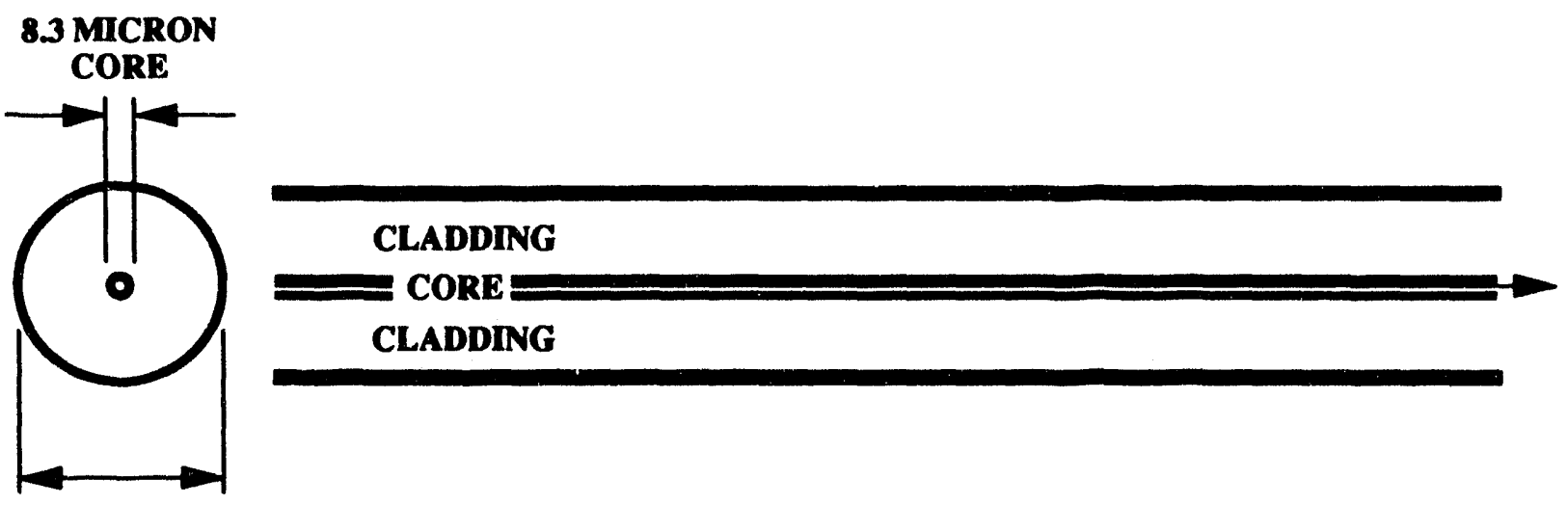

125 MICRON

CLADDING

Figure 3. Single Mode Optical Waveguide (allows one path of light to propagate) 


\section{Optical Connectors and Couplers}

Th achieve maximum end-to-end transmission capabilities, optical connectors and couplers must match the physical parameters of the fiber they terminate. At Sandia, the standard optical connector and coupler for Multimode and Single Mode fiber is the ST (Straight Tip). Multimode and Single Mode ST connectors and couplers differ only in alignment component dimensional tolerances. Single Mode connectors and couplers have more precise tolerances and associated higher costs. These high-quality connectors and couplers have also been adopted by many national standards committees.

\section{Optical Temination Panels}

There are two types of optical termination panels used at Sandia for intra-building cabling: the user outlets and the Intermediate Distribution Room (IDR) panels. Optical fiber panels must accommodate the number of cables and conductors required by the SAND93-0002 cabling standard.

The standard telecommunications cable configuration for each user outlet at SNL/NM is three 4-pair, high-quality, Unshielded Twisted Pair (UTP) cables; one 4-fiber Multimode cable; and one 4-fiber Single Mode cable. The standard user outlet is shown and described in SAND93-0002.

Buildings within Sandia's Secure Tech Area will be cabled with two identical cabling distribution systems: one black for Open/Restricted Access and one red for Secure telecommunications needs.

The standard IDR optical termination panel is capable of housing 24 optical fibers and is shown and described in SAND93-0002. Each IDR is capable of servicing hundreds of users. Therefore, the resultant number of optical fibers terminating in an IDR is high and requires extreme attention to space allocation for termination.

\section{Optical Splices}

At Sandia, mechanical splices have been used for cable-cut emergency restoration. Fusion splicing is being used to minimize optical reflectivity in the Lab-wide Single Mode trunk which is nearing completion. Splicing will not be discussed in this document because of its limited application.

\section{Optical Test Equipment}

There are three basic types of optical test equipment used to verify installed end-to-end transmission capabilities. They are:

- Optical Loss Test Set or Optical Sources \& Power Meters

- Optical Time Domain Reflectometer

- Optical Frequency Spectrum Analyzer.

\section{Optical Loss Test Set (OLTS)}

An OLTS (commonly referred to as an attenuation meter) contains both an optical source and an optical power meter in one instrument. Optical sources and power meters with automated dual wavelength bi-directional attenuation and optical return loss (ORL) testing capabilities are preferred at Sandia for end-to-end testing of individual optical paths. An optical source typically injects a constant-wave frequency of light into an optical path. The power meter displays the amount of light received after propagating the optical path. The amount of light received is compared to the amount of light injected. The difference (minus the interconnection jumper losses) represents optical attenuation. It is most often expressed as power loss in units of decibels (dBs). It can also be expressed in units of milliWatts (mWs). The accuracy of the results is dependant on source and meter circuitry tolerances and operational procedures. Proper operational procedures, including consistency and frequent referencing, along with high-quality equipment can yield accurate, repeatable, power-loss measurements.

Optical attenuation is one of the most important transmission limitation factors for both Multimode and Single Mode fibers. ORL is an additional critical transmission parameter for Single Mode components due to the detrimental affect on LASER sources caused by reflections. Large back reflections can cause LASER sources to experience thermal variations which in turn cause both frequency and power stability problems. At Sandia, attenuation and ORL are measured with optical sources and power meters 
incorporating dual wavelength bi-directional automated test features. This allows end-to-end testing of individual optical paths. Optical attenuation and ORL information obtained from this equipment is absolutely necessary for optical circuit design.

\section{Optical Thme Domain Reflectometer (OTDP)}

Optical Time Domain Reflectometers can provide optical fiber and event loss as well as fiber length measurements. OTDRs contain both an optical source and a receiver. The ability to operate this device by a single person is an inherent advantage. CTDRs are excellent for immediate assessment of connector, splice, and fiber quality. They are indispensable for troubleshooting optical paths. Relatively large loss events (broken fibers, crashed/dirty connectors, etc.) can be located within inches or feet of their occurrence.

\section{Optical Frequency Spectrum Anabyer}

At Sandia, frequency spectrum analysis of an optical path is not typically required. The highquality optical components (fibers, connectors, and couplers) required by Sandia bring with them guaranteed bandwidth specifications as stated by published manufacturing test results.

NOTE: The Attenuation/ORL test set included in the preferred test equipment listed in Table 1 incorporates both portability and accuracy. The OTDR incorporates extreme accuracy and has been used repeatedly in previous optical cable installations at Sandia. Optical test equipment other than the preferred items listed in Table 1 must be approved by Sandia Department 1955 prior to usage. All optical test equipment must be calibrated and certified in good working condition in accordance with the equipment manufacturers' recommendations.

\begin{tabular}{|c|c|c|c|}
\hline Equipment & Manufacturer & Model & Description \\
\hline \multirow[t]{2}{*}{$\begin{array}{l}\text { Optical Fiber } \\
\text { Attenuation/ } \\
\text { ORL Test Sets }\end{array}$} & EXFO & $\begin{array}{l}\text { Multimode } \\
\text { \#FOT-913-12D-32 }\end{array}$ & $\begin{array}{l}\text { Dual Wavelength } 850 / 1300 \mathrm{~nm} \\
\text { LED source with ST connector and } \\
\text { InGaAs sensor }\end{array}$ \\
\hline & & $\begin{array}{l}\text { Single Mode } \\
\text { "FOT-913-BR23BLC-74 }\end{array}$ & $\begin{array}{l}\text { Dual Wavelength } 1310 / 1550 \mathrm{~nm} \\
\text { Cooler LASER with ST/PC connec- } \\
\text { tor and InGaAs sensor }\end{array}$ \\
\hline \multirow[t]{3}{*}{$\begin{array}{l}\text { Optical Fiber } \\
\text { OTDR }\end{array}$} & TEKTRONICS & $\begin{array}{l}\text { TFP2 FiberMaster with } \\
\text { plug-in modules }\end{array}$ & \\
\hline & & $\begin{array}{l}\text { Multimode } \\
\text { FM8513-Option } 24\end{array}$ & $\begin{array}{l}\text { Dual Wavelength } 850 / 1300 \mathrm{~nm} \\
\text { source with ST PC connector }\end{array}$ \\
\hline & & - FM1315-Option 34 & $\begin{array}{l}\text { Dual Wavelength } 1310 / 1550 \mathrm{~nm} \\
\text { source with ST PC connector }\end{array}$ \\
\hline \multirow[t]{2}{*}{$\begin{array}{l}\text { EUTP Cable } \\
\text { Tester }\end{array}$} & Wavetek & LANTech 100 & $\begin{array}{l}\text { Multifunction tester capable of test- } \\
\text { ing } 100 \text { Mbit Category } 5 \text { UTP }\end{array}$ \\
\hline & \multicolumn{3}{|c|}{$\begin{array}{l}\text { Note: As of November 1993, several other companies such as Microtest, Fluke, and } \\
\text { HP are developing similar EUTP test equipment. This test equipment may prove to } \\
\text { be acceptable, but must be approved by Sandia Department } 1955 \text { prior to use. }\end{array}$} \\
\hline
\end{tabular}




\section{Optical Test Procedures}

\section{Pre-test Training}

Direct connectorization (assembling a connector onto the end of an optical fiber) involves many complex assembly procedures. Training facilities, typically operated by optical component manufacturers, offer certification for specific optical products. All personnel involved in optical connectorization activities at Sandia must be certified by training facilities approved by Sandia Department 1955.

\section{Teat Data Forms}

Sample forms for recording cable lengths, test data, and calculation results are included in the "FORMS" section of this document. These forms are available from Sandia Department 1955.

\section{Optical Cable Length Measurement}

The length of each optical fiber cable must be determined from the length markings on the cable jacket. AT\&T cable jacket markings are in feet; however, determining both the Predicted Total Attenuation and Calculated Optical Attenuation requires length in meters. All cable lengths in feet and meters must be included in the final report.

\section{Optical Test Equipment Setup}

The optical test equipment must be properly adjusted prior to use. The user must follow the detailed setup instructions in the test meter instruction manual(s). The variable unit adjustments on the test equipment must be calibrated to match the cable manufacturer's stated cable transmission parameters. Typical OTDR setup requirements include inputting the cable's group index " $\mathrm{N}$ " as defined by the cable manufacturer.

The group index is a complex value based upon several optical cable properties: the test wavelength, refractive index profile, modal conditions (in Multimode fiber), and fiber length.

The index of refraction " $n$ " for an optical fiber is defined as the speed of light in a vacuum " $c$ " divided by the speed of light (or velocity of propagation) in the fiber "v." The typical value of " $n$ " in fused quartz glass is 1.46.

\section{Connector Valldation Test}

As each optical connector assembly is completed, an OTDR must be used to assess immediate acceptance or rejection of the connector assembly. The connector assembly will be accepted if the loss displayed on the OTDR trace does not exceed the connector manufacturer's published mean loss and standard deviation value. Connector assemblies exceeding the manufacturer's mean loss and standard deviation value will be rejected. They must be replaced and tested with the OTDR until acceptance.

\section{Optical Reference Level Measurement}

An optical source must be connected to a power meter with a short (2-3 meter) jumper cable. The jum per cable must have identical transmission characteristics as the optical path being measured. Operationul stabilization (primarily thermal) must be reached by the optical sources prior to any measurements. After stabilization, the received power levels in $\mathrm{dBm}$ must be recorded. This procedure to obtain reference levels must be repeated every 30 minutes during the measurement process to verify the integrity of the jumper and the source. The same optical sources and power meters should be used for all measurements to ensure consistency.

\section{Optical Path Loss Measurement}

End-to-end optical attenuation must be measured after both ends of an optical fiber have been connectorized, dressed and mounted in outlets or panels. This should represent a fiber's final physical configuration. At this point, the endto-end attenuation can be measured and recorded with optical sources and power meters.

A source must be connected to one end (A) of the optical path to be measured and a power meter connected to the other end (B). The received power level (A to B) must be recorded in $\mathrm{dBm}$ for each applicable wavelength. The locations of the source and power meter must then be reversed. The received power level (B to A) must be recorded in $\mathrm{dBm}$ for each applicable wavelength. The two reconded power levels for each applicable wavelength must then be averaged and recorded in $\mathrm{dBm}$. The reference level for each 
wavelength must be subtracted from the average and recorded in $\mathrm{dB}$. This value will be the "calculated optical attenuation" of the optical path for each wavelength.

This procedure must be repeated for all optical paths. All of the measured and calculated values must be included in a final report.

Additionally, all Single Mode optical paths must be measured for optical return loss. This can be accomplished by the use of the Sandia preferred attenuation/ORL test sets listed in Table 1.

\section{Optical Path Acceptance Criterla}

The "calculated optical attenuation" for each optical path must not exceed the Predicted Total Attenuation (PTA). The PTA must be calculated with the following formula:

$$
\mathrm{PTA}=(\mathrm{CoQ} \times \mathrm{CoA})+(\mathrm{CaL} \times \mathrm{CaA})
$$

where: PTA $=$ Predicted Total Attenuation in $\mathbf{d B}$

$$
\begin{aligned}
& \text { CoQ = Connector Quantity } \\
& \mathbf{C o A}=\text { Connector Attenuation in } \mathrm{dB} \\
& \mathrm{CaL}=\text { Cable Length in } \mathbf{k m} \\
& \mathrm{CaA}=\text { Cable Attenuation in } \mathrm{dB} / \mathrm{km}
\end{aligned}
$$

The following values were derived from hardware vendor specifications:

CoA (MM or SM)

for STII connectors $=0.35 \mathrm{~dB}$

$$
\begin{aligned}
& \mathrm{CaA}(\mathrm{MM})=3.4 \mathrm{~dB} / \mathrm{km} @ 50 \mathrm{~nm} \\
& 1.0 \mathrm{~dB} / \mathrm{km} \text {. } 1300 \mathrm{~nm} \\
& \mathrm{CaA}(\mathrm{SM})=0.4 \mathrm{~dB} / \mathrm{km} \text {. } 1310 \mathrm{~nm} \\
& 0.3 \mathrm{~dB} / \mathrm{km} \text { @ } 1550 \mathrm{~nm}
\end{aligned}
$$

PTA calculation example for MM fiber at 850 nm:

$$
\begin{aligned}
\text { PTA }= & (2 \times 0.35 \mathrm{~dB})+(0.15 \mathrm{~km} \times \\
& 3.4 \mathrm{~dB} / \mathrm{km}) \\
= & 0.7 \mathrm{~dB}+0.51 \mathrm{~dB} \\
= & 1.21 \mathrm{~dB} \\
= & 1.2 \mathrm{~dB} \text { rounded to nearest } \\
& \text { tenth of a dB }
\end{aligned}
$$

PTA calculation example for SM fiber at 1310 nm:

$$
\begin{aligned}
\text { PTA }= & (2 \times 0.35 \mathrm{~dB})+(0.15 \mathrm{~km} \times \\
& 0.4 \mathrm{~dB} / \mathrm{km}) \\
= & 0.70 \mathrm{~dB}+0.06 \mathrm{~dB} \\
= & 0.76 \mathrm{~dB} \\
= & 0.8 \mathrm{~dB} \text { rounded to nearest } \\
& \text { tenth of } \mathrm{a} \mathrm{dB}
\end{aligned}
$$

Any optical path with a "calculated optical attenuation" exceeding its predicted total attenuation must be documented as unacceptable and the optical path problem must be identified and corrected.

The authority to abandon an unacceptable optical path after thorough attempts to correct the problem is solely owned by Sandia Department 1955.

\section{Optical Return Loss Measurement}

Single Mode connectors should have a median return loss of $-42 \mathrm{~dB}$ and a maximum return loss of -35 dB. Any Single Mode connector with an ORL exceeding the maximum return loss must be replaced and tested until acceptance.

\section{Final Optical Test Report}

A final optical test report which confirms that the optical cabling infrastructure has been tested utilizing the procedures contained within this document must be delivered to Sandia, Department 1955, within 4 weeks after completion of the installation. The report must include cable test data, measurements and calculations for all installed cables as shown in the cable test forms in the "FORMS" section of this document. Sandia-preferred handheld test sets can perform many of the required tests simultaneously, greatly reducing testing time and labor costs.

The testing contractor must submit three copies of the test report. Optical fiber and UTP reports will be combined on the cable test forms.

Each report copy will be labeled and submitted in a white, 2-inch, three-ring view-binder. Each report copy will include:

- All completed cable test forms as described above, bound in order by room number.

- All certificates of optical test equipment calibration/certification. 
- All certificates of training for test personnel.

- Any other information as needed to document the testing of the cable infrastructure.

- A written statement of compliance with SAND93-1076.

- A written statement assuring Optical Fiber and Unshielded Twisted Pair performance of the entire installation for a period of 5 years starting from the day of acceptance.

\section{Unshielded Twisted Pair as a Transmission Media}

\section{Background}

Before the advent of optical fiber, copper conductors were the prime choice for communications cabling. Even though better conducting materials were available (such as gold), copper provided the best balance between good conductance, cost, and material availability.

Today's technology allows data to be transmitted on Enhanced Unshielded Twisted Pair (EUTP) copper lines at 100 million bits per second and greater. At this speed, all the information contained in an entire set of encyclopedias could be transmitted in one minute! This high-speed data capability does not come easily. It requires high-purity copper, precision twisting of the wire pairs, careful installation, and matched precision components. Its primary limitation (derived from national and international standards) is a maximum transmission distance of 100 meters or approximately 300 feet. This makes EUTP an excellent option for intra-building cabling.

In spite of new high-speed UTP systems, optical fiber is still the preferred data transmission media for future communications systems. When compared to high-speed UTP systems, they can deliver even greater quantities of data, transmit over longer distances, and provide more immunity to external sources of interference. However, the new high- speed UTP applications are currently useful for several reasons:

- UTP cabling is still convenient for use with existing copper-based equipment.

- UTP speeds are often satisfactory for systems that do not require massive quantities of data transfer.

- UTP is still more cost effective for short runs due to the relatively higher cost of optical fiber connectors and terminations.

- UTP cabling and electronic components are currently cheaper than comparable optoelectronic components, although the trend over the past 10 years has brought both costs much closer together.

\section{UTP Components}

UTP components utilized at Sandia include copper cables, connectors, termination frames, patch panels, and splices. Specific UTP components to be used at SNL/NM are listed and described in SAND93-0002. The following are general descriptions of each component.

\section{UTP Cables}

UTP communications cables for high-speed applications may appear similar to regular telephone cables, but are in fact quite different. Extended frequency UTP cables are made of highpurity copper, have special precision pair twisting, and use special jacketing materials. Specialized installation procedures are also required as these cables are sensitive to bending, kinking, and overstressing.

Pair twisting is a critical parameter. The EUTP cables at Sandia consist of 4-pair cables. Each of the four pairs within a cable has a different angle of twist. This not only reduces crosstalk (signal coupling) between the two conductors of a pair, but also minimizes crosstalk between pairs within a cable.

EIA/TIA-569 TSB-40 specifies three highspeed UTP cable types for interior usage, and designates them as Categories 3, 4, and 5:

- Category $3=\max .16 \mathrm{MHz}, 10 \mathrm{Mbps}$.

- Category $4=\max .20 \mathrm{MHz}, 16 \mathrm{Mbps}$.

- Category $5=\max .100 \mathrm{MHz}, 100 \mathrm{Mbps}$. 
AT\&T has recently developed a 4-pair UTP cable capable of transmission rates up to 155 Mbps and beyond. AT\&T designates this cable and associated termination components as their HIGH-5 product line. All 4-pair UTP cabling at SNL/NM is specified as AT\&T HIGH-5 to provide maximum capability for any user who occupies a building at Sandia.

\section{UTP Connectors}

4s with optical connectors, UTP connectors must also match their cable's physical parameters to maintain the cable's maximum end-toend trensmission capability. For intra-building cabling at Sandia, the standard UTP connector is an AT\&T HIGH-5 RJ-45 modular jack with pin configurations as designated per EIA/TIA568, T568A.

\section{UTP Termination Frames}

The IDR UTP frames must match their cable's physical parameters and accommodate the large number of cables and conductors required by this standard. Termination frames must accommodate Sandia's cable/conductor configuration and space limitation requirements. AT\&T 110 termination frame and components are HIGH-5 and allow extremely dense termination of UTP conductors. This termination frame also provides consistent, reliable, repeatable, gas-tight connections for data, voice, and other low-voltage circuits. Each frame is capable of terminating 3600 wire pairs.

\section{UTP Patch Panels}

Patch panels and jumper cables must also be HIGH-E to maintain the UTP cables' data transfer capabilities. Patch panels, panel connectors, jum per cables, and jumper cable connectors are HIGH-5 RJ-45 modular jacks with pin configurations as designated per EIA/ TIA-568, T568A or AT\&T 110 termination components.

\section{UTP Spllcing}

At Sandia, splicing has been used for cablecut emergency restoration, but is not a part of normal cable installation. Splicing is NOT permitted in any intra-building cabling and will not be discussed in this document because of its limited applications.

\section{UTP Test Equipment}

There are eight basic iypes of UTP test equipment used to verify installed end-to-end transmission capabilities. They are:

- ohm meter

- terminators

- time domain reflectometer (TDR)

- noise meter

- line mapper

- high-frequency signal generator

- capacitance meter

- power meter

\section{Ohmmeter}

The function of an ohmmeter is often included as part of a multimeter or volt-ohm-milliammeter (VOM). It is typically used to measure continuity of a conductor by testing for a short circuit or a known resistance applied across the opposite end of the conductor. Although ohmmeters are commonly used to validate coaxial cabling systems, they alone are not sufficient to validate unshielded twisted pair media.

\section{Terminators}

Terminators end a cable segment under test by providing either a short, circuit or several known resistances for matching wire pairs. Shorting terminators may not detect shorts due to cable damage. Impedance-matching terminators provide more reliable test information because they closely approximate actual system working conditions. Intelligent terminators contail. on-board circuitry and can transmit and receive to work in conjunction with a handheld test meter.

\section{Time Domain Reflectometer (TDR)}

A TDR is used to determine cable length and locations of impedance mismatch. It transmits a fast rise-time pulse down a conductor and then monitors for pulse reflections. Impedance mismatches cause reflections which can be displayed on an oscilloscope-like screen or a numerical display. While most defects cause minor reflections, the end of a conductor (or a break) produces a major reflection. The cable's length or the location of a defect may be calculated by combining a pulse reflection's travel time with the conductor's nominal 
velocity of propagation (NVP). (Typically a fractional value of the speed of light, NVP is provided by the cable manufacturer.)

\section{Nolse Meter}

A wide-band AC noise meter can detect problems from EMI and RFI by measuring the strengths of unwanted signals and analyzing the frequencies of induced line noise, thereby aiding in the identification of the noise sources. Although shielded cable is less susceptible to line noise than UTP, properly twisted UTP cable can provide reliable high-speed data transmissions at a lower cost. Installing the UTP cables in grounded metallic conduit can further reduce the cables' vulnerability to electronic disturbances. However, UTP can act as an antenna for electronic noise from such sources as fluorescent lighting, motors, broadcast equipment, and microwaves. UTP cabling should NOT be installed near these devices.

\section{Line Mapper}

Line mappers (or end-to-end connectivity testers) verify the end-to-end connectivity for each conductor in a UTP cable. Sandia 4-pair UTP cables are terminated with an eight-pin rnodular jack (RJ-45) configured per EIATIA 1568A. This cabling and connector set looks much like telephone wiring, but has a different wiring configuration. A line mapper uses a loopback terminator and light-emitting diodes (LEDs) to verify proper termination. Advanced units also detect open and shorted circuits and provide conductor status printouts.

\section{High-Frequency Signal Generator}

A high-frequency signal generator simulates the live conditions of a fully loaded network. A stable, preset signal source is needed to accurately measure attenuation and crosstalk. A square wave output is needed to accurately simulate network data traffic, but a sine wave output can produce an effect adequate for obtaining characteristic cable performance measurements.

\section{Capacitance Meter}

A capacitance meter tests for conductor damage. It compares measured capacitance on an open-ended cable pair with factory-specified nominal values or accepted industry-standard EIA/TIA values. A pair's mutual capacitance will change if it has been overstressed during installation.

\section{Power Meter}

The power meter receives input from the high-frequency signal generator. It measures the strength of the received signal at the far end of a pair. When the received signal strength is compared to the source strength, the transmitted power loss (attenuation) can be calculated. Near-end crosstalk may also be measured by attaching the signal generatur and the power meter to the same end of different pairs.

\section{Multifunction Test Sets}

Modern technology has recently combined all of the required UTP test equipment into a single handheld unit. It is highly recommended that the UTP cabling tests be performed with the new multifunction handheld test units for several reasons:

- Individual test equipment pieces would cost approximately three-to-four times the cost of a single handheld multifunction unit.

- Handheld units are conveniently portable and easy to manipulate.

- Handheld units provide one-button multifunction autotesting and simple pass/ fail results which reduce testing time and human errors.

- Handheld units can provide advanced features such as internal storage of many test results, variable printout options, and direct test data downloading into computer databases.

- Handheld units can have all test functions calibrated simultaneously by a single manufacturer.

\section{UTP Test Procedures}

\section{Background}

Studies have shown that poor cable and connector installation practices can drastically de- 
grade cabling performance. While cabling problems may account for 70 percent of all LAN problems, these cabling problems can be largely eliminated through proper cable installation and testing techniques. Expensive network downtime can be avoided and maintenance costs dramatically reduced when a cabling infrastructure is properly installed and tested.

The test procedures for UTP cabling are not as complex as the provedures for fiber-optic testing. However, EUTP cabling is far more sensitive than typical telephone cabling. For example, it cannot be kinked, stretched, or untwisted. EUTP must be more carefully installed and more rigorously tested to ensure its ability to transmit high bit-rates. Terminations and connections must be made in accordance with the cable and connector manufacturer's specifications. For example, the wire pairs cannot be untwisted more than 1/2 inch at the points of termination or crosstalk data errors will occur. All personnel involved in EUTP cable installation, termination, or connecting activities at Sandia must be fully aware of the hardware manufacturers' installation requirements and the following Sandia UTP test methods.

End-to-end testing must be measured after both ends of a cable have been connectorized and mounted in outlets, panels, or frames. This should represent a cable's final physical configuration. At this point, the required tests may be performed and the test information recorded for submittal in the final test report. Loss and interference values will encompass the sum of the end-to-end effects, including contributing factors from both the cable and the connectors. Cables and/or connector assemblies which do not test within the manufacturer's accepted test values will be rejected. They must be replaced and tested until acceptance. Each EUTP cable test is intended to have a simple pass or fail result as shown on the cable test forms in the "FORMS" section of this report.

\section{Test Data Forms}

Sample forms for recording cable lengths, test data, and calculation results are included in the "FORMS" section of this document. These forms are available from Sandia Department 1955.

\section{Dally Test Equipment Preparation}

UTP cable test equipment must be properly configured each day before testing begins. The following five checks must be made:

- Verify that the test equipment is still within its manufacturer's calibration w/arranty, as some manufacturers require that they annually recalibrate and recertify their test equipment.

- Verify that the tester is set to auto-test and the proper cable type is selected, e.g., 10BaseT, Category 3, 4, or 5.

- Verify that the tester's selected nominal velocity of propagation (NVP) matches the cable being tested. NVP values should be taken from each cable manufacturers' specifications. Average industry NVP values are shown in Table 2 for reference only.

- Perform a test meter "self-test" to confirm that the meter is functioning properly.

- Connect the tester to its matched "smart" terminator (via the test equipment manufacturer's test cable) and perform an autotest to confirm that the meter and terminator are functioning properly together.

\begin{tabular}{lc}
\hline \hline \multicolumn{2}{c}{ Table 2. Average Industry NVP Values } \\
\multicolumn{2}{c}{ Cable Type-NVP } \\
10Base T & .65 \\
16MB Token Ring & .71 \\
4MB Token Ring & .65 \\
EIAVUL Cat 3 & .65 \\
EIAVUL Cat 4 & .71 \\
EIAVUL Cat 5 & .75 \\
USOC & .65 \\
\hline \hline
\end{tabular}

After a successful series of these daily equipment checks, actual cable testing can begin. Use the appropriate test data forms in the "FORMS" section of this document to record the cable test results. Selecting the cable tester's auto-test fea- 
ture with the Sandia-preferred test equipment should execute the following tests:

\section{Test *1 - Line Mapping (End-to-End Connectivity)}

A cable test meter is connected to one end of the cable to be tested and its terminator (commonly referred to as intelligent, smart, or remote) is connected to the other end of the cable. All four pairs are then checked for proper wiring configuration: open conductors, shorted conductors, crossed pairs, and reversed pairs. The results of these tests are recorded as either pass or fail for each pair. Fdilures require repair or replacement as necessary and retesting until passing results are achieved.

\section{Test \#2 - Loop Reslstance (DC - Steady State)}

An ohmmeter is connected across one end of a cable pair, with a shor'ir.g terminator across the other end of the cable pair. The steady-state DC resistance is measured in ohms and compared to the cable manufacturer's standard values. The permitted values and measured values will increase with longer segments of cable. The test equipment reports the ohms resistance value for recording. Values greater than the allowable resistance are considered fail. Values smaller than the allowable resistance will pass. The result of this test is recorded as either pass or fail. Failed tests include recording the measured resistance. Failures require repair or replacement and retesting until passing results are achieved.

\section{Test \#3 - Near End Crosstalk (NEXT)}

NEXT is the tendency for signals travelling in one pair of wires to be induced into an adjacent wire pair. This effect is typically the greatest at connection points where the pairs are untwisted. NEXT is measured in $\mathrm{dB}$. The amount of induced signal beyond the reference level is recorded. A source must be connected to one pair while an adjacent pair is tested. Impedance-matched terminators (100 ohms) should be used. The test frequencies and permitted $\mathrm{dB}$ crosstalk values at each tested frequency will be as specified in EIA TIA TSB 36 for category five UTP cable. The results of the test will be pass or fail. Failed tests (crosstalk dB values smaller than those specified) include recording both the measured crosstalk signal in $\mathrm{dB}$ and the frequency at which it failed. Failures require repair or replacement and retesting until passing results are achieved. It is not necessary to record passing NEXT values for the Signal-to-Noise Ratio (SNR) calculation if the test equipment automatically calculates and reports the SNR. Refer to the "Signal-to-Noise Ratio Test" at the end of this section.

\section{Test $\# 4$ - Attenuation}

Attenuation is measured by transmitting several signals at increasing frequencies across each conductor. The strength of the received signal is compared to the strongth of the transmitted signal. The test equipment may physically measure millivolt signal loss, but should report the loss in units of decibels (dB). The signal loss will normally increase at higher frequencies. The test frequencies and permitted $\mathrm{dB}$ loss values at each tested frequency will be as specified in EIA TIA 568 category five attenuation specifications for UTP cable. The results of the test will be pass or fail. Failed tests (attenuation dB values greater than those specified) include recording both the measured signal loss in $\mathrm{dB}$ and the frequency at which it failed. Failures require repair or replacement and retesting until passing results are achieved. It is not necessary to record passing attenuation values for the SNR calculation if the test equipment automatically calculates and reports the SNR. Refer to the "Signal-to-Noise Ratio Test" at the end of this section.

\section{Test $: 5$ - Cable Length}

Cable length must be recorded from the length markings on each cable jacket. Lengths are currently marked in feet, and will also be recorded in feet. Cables longer than 295 feet (90 meters) should be noted in the length report as these cables may have data transfer limitations.

Cable length may be verified electronically with a time domain reflectometer (TDR) and the cable's manufacturer-specified nominal velocity of propagation (NVP). If an electronic TDR length verification is made, record any TDR cable length which measures more than 20 feet different than the recorded cable jacket length. 


\section{Test $" 6$ - Capacitance}

When an EUTP cable is damaged, stretched, or improperly terminated, its mutual capacitance will change. Each twisted pair is tested with a capacitance meter. The opposite end of the pair being tested is open circuit. The capacitance between each wire pair (mitual capacitance) is measured and recorded in picofarads (pf). The measured capacitance is then divided by the cable length (recorded above from the cable jacket in the length test) to obtain the capacitance per foot (p/ft). EIA/TIA TSB 36 limits the maximum mutual capacitance of category five UTP cable to $17 \mathrm{nf} / 1000 \mathrm{ft}$ or $17 \mathrm{pf} / \mathrm{ft}$. Properly installed UTP cabling should yield capacitance test results within 2 percent of the cable manufacturer's specification. The result of this test is pass or fail. An occurrence of a pair with mutual capacitance levels greater than $17 \mathrm{pf} / \mathrm{ft}$ is recorded as a failure. Failed tests include recording the measured mutual capacitance, and the cable and the failed pair in which it occurred. Failures require repair or replacement and retesting until passing results are achieved.

\section{Additlonal Testing}

Additionally, the following tests may be useful for troubleshooting but are not required for cable certification when the above six tests have passed:

Electrical Noise (FMT/REI) Test. Electrical noise is caused by random stray voltages induced into the data transmission cabling. There are two types of electrical noise tests: impulse noise and average noise.

The impulse noise test requires a voltmeter or oscilloscope to monitor each cable pair for more than 10 seconds and record any induced voltage surges or spikes with a duration of 20 nanoseconds or greater. IEEE 802.3 10BASET specifications define unacceptable impulse noise conditions as more than two occurrences of voltage greater than 264 millivolts within a continuous 10-second monitored time window. The result of this test is recorded as either pass or fail. Failed tests include recording the number of unacceptable spikes and surges within the 10-second testing window, and the millivolt value of the maximum recorded surge or spike.
Failures should be documented on the test forms.

The average noise test is made with a wideband AC noise meter. The intent is to detect and identify EMIRFI on the UTP lines. The cable being tested is terminated with its characteristic impedance (typically $100 \mathrm{ohms}$ ) and examined for EMI/RFI in three frequency bands:

- $0 \mathrm{~Hz}$ to $150 \mathrm{kHz}$ (typical sources - AC lines, intercoms, telephones, blower motors, elevator equipment)

- $150 \mathrm{kHz}$ to $20 \mathrm{MHz}$ (typical sources - light dimmers, medical equipment, computers, copiers, laser printers)

- $20 \mathrm{MHz}$ to $1 \mathrm{GHz}$ (typical sources - radios, cellular phones, TVs, microwave ovens, broadcast equipment)

The result of this test is pass or fail. An occurrence of RMS noise levels greater than 100 millivolts in any of these three frequency bands is recorded as a failure. Failed tests include recording both the measured noise level in millivolts and the frequency band in which it occurred. Failures should be documented on the test forms.

Cable Impedance Test (dynamic). Impedance is the combined result from the dynamic effects of resistance, inductance, and capacitance. A cable's impedance will vary at different frequencies of data transmission. Cable manufacturers will list a nominal (average) impedance for their UTP cable at a specific frequency, for example, $100 \mathrm{ohms}$ at $10 \mathrm{MHz}$. Each cable's absolute impedance will be measured via TDR technology at critical frequencies and appropriate incremental steps of frequency change. Each measured impedance will be examined and averaged along the length of the cable. For example, the sweep frequencies should be from $500 \mathrm{kHz}$ through $100 \mathrm{MHz}$ at incremental steps of $500 \mathrm{kHz}$. The results of the test will be pass or fail. The average measured impedance values at each test frequency must be within 15 percent of the manufacturer's specified values at each test frequency to pass; for example, a specified $100 \mathrm{ohms}$ would pass if measured within 85 to $115 \mathrm{ohms}$. Note that split pairs may 
exhibit 20 to 30 ohms impedance fluctuation, which will result in test failure. Failed tests include recording both the measured impedance in ohms and the frequency at which it failed. Failures should be documented on the test forms.

Sional-to-Noise Ratio (SNR) Test. The SNR is the mathematical value in $\mathrm{dB}$ of worst-case NEXT minus worst-case attenuation measured at the same test frequency. The results of the test will be pass or fail. Failed tests (SNR dB values smaller than $10 \mathrm{~dB}$ for $10 \mathrm{Base} \mathrm{T}$ or $5 \mathrm{~dB}$ for Cat.5) include recording both the calculated SNR value in $\mathrm{dB}$ and the frequency at which it failed. Failures should be documented on the test forms. Ideally, a passing NEXT sind a passing attenuation should generate a passing SNR.

\section{Final UTP Test Report}

A final UTP test report which confirms that the UTP cabling infrastructure has been tested utilizing the procedures contained within this document must be delivered to Sandia Department 1955 within 4 weeks after completion of the installation. The report must include pass/ fail results and/or actual cable test data and required cable measurements and/or calculations for all installed cables as shown in the cable test forms in the "FORMS" section of this document.
Sandia's preferred handheld test units and intelligent terminators can perform many of the required tests simultaneously, greatly reducing testing time and labor costs.

The testing contractor must submit three copies of the test report. UTP and optical fiber reports may be combined if the cable test forms contain space to record both cable tests.

Each report copy will be labeled and submitted in a white, 2 -inch, three-ring view-binder(s). Each report copy will include:

- All completed cable test forms as described above, bound in order by room number.

- An installer-signed statement of compliance with SAND93-1076.

- All certificates of UTP test equipment calibration/certification.

- All certificates of training for test personnel.

- Any other information as needed to document the testing of the cable infrastructure.

- A written statement of compliance with SAND93-1076.

- A written statement assuring Optical Fiber and Unshielded Twisted Pair performance of the entire installation for a period of 5 years starting from the day of acceptarice. 


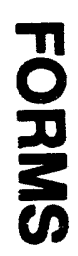




\section{BLACK Outlet Cable Test Form}

Bullding Number -

Test Date -
From: IDR Name -

Outlet Box Number -
To: Room Number -

Outlet Type -

\section{UTP CABLE,}

\begin{tabular}{|c|c|c|c|c|c|c|c|}
\hline & $\begin{array}{l}\text { Cable Length ( } \mathrm{t} \text { ) } \\
\text { from Jacket marks }\end{array}$ & $\begin{array}{l}\text { Test \#1 } \\
\text { Line Map }\end{array}$ & $\begin{array}{c}\text { Test " } 2 \\
\text { Loop Resistance }\end{array}$ & $\begin{array}{l}\text { Test *3 } \\
\text { NEXT }\end{array}$ & $\begin{array}{c}\text { Test :4 } \\
\text { Altenuation }\end{array}$ & $\begin{array}{l}\text { Test \#5 } \\
\text { Length }\end{array}$ & $\begin{array}{c}\text { Test } \because 6 \\
\text { Capacitance }\end{array}$ \\
\hline VOICE CABLE & & Pass / Fail & Pass / Fail & Pass / Fail & Pass / Fail & Pass / Fail & Pass / Fail \\
\hline DATA CABLE :1 & & Pass / Fail & Pass / Fail & Pass / Fail & Pass / Fail & Pass / Fail & Pass / Fail \\
\hline DATA CABLE $\# 2$ & & Pass / Fail & Pass / Fail & Pass / Fail & Pass / Fail & Pass / Fail & Pass / Fail \\
\hline
\end{tabular}

\section{OPTICAL FIBER CABLE}

Test Wavelength $=850 \mathrm{~nm}$

\begin{tabular}{|c|c|c|c|c|c|c|c|}
\hline Fiber * & $\begin{array}{l}\text { Cable Length (t) } \\
\text { from Jacket marks }\end{array}$ & $\begin{array}{c}\text { A to } 8 \text { loss } \\
\text { d8m }\end{array}$ & $\begin{array}{c}\text { B to A loss } \\
0 \mathrm{~mm}\end{array}$ & $\begin{array}{c}\text { Average loss } \\
08 \mathrm{~m}\end{array}$ & $\begin{array}{c}\text { Optical } \\
\text { Roterence } \\
\text { Level (AB) }\end{array}$ & $\begin{array}{c}\text { Calculated } \\
\text { Optical } \\
\text { Altenuation (dB) }\end{array}$ & $\begin{array}{c}\text { Predicted } \\
\text { Total } \\
\text { Attenuation (dB) }\end{array}$ \\
\hline \multicolumn{8}{|l|}{1} \\
\hline \multicolumn{8}{|l|}{2} \\
\hline \multicolumn{8}{|l|}{3} \\
\hline \multicolumn{8}{|l|}{4} \\
\hline Fiber * & $\begin{array}{l}\text { th = } 1300 \mathrm{~nm} \\
\text { Cable Length (tt) } \\
\text { from Jacket marks }\end{array}$ & $\begin{array}{c}\text { A } 10 \text { B loss } \\
\text { dem }\end{array}$ & $\begin{array}{c}\text { B } 10 \text { A loss } \\
\mathrm{dem}\end{array}$ & $\begin{array}{c}\text { Average loss } \\
\text { orm }\end{array}$ & $\begin{array}{l}\text { Optical } \\
\text { Peterence } \\
\text { Level (dB) }\end{array}$ & $\begin{array}{c}\text { Calculated } \\
\text { Optlcal } \\
\text { Altenuation (dB) }\end{array}$ & $\begin{array}{c}\text { Predicted } \\
\text { Total } \\
\text { Altenuation (dB) }\end{array}$ \\
\hline \multicolumn{8}{|l|}{1} \\
\hline \multicolumn{8}{|l|}{2} \\
\hline \multicolumn{8}{|l|}{3} \\
\hline 4 & & & & & & & \\
\hline
\end{tabular}

\section{SM OPTICAL FIBER CABLE}

Test Wavelength $=1310 \mathrm{~nm}$

\begin{tabular}{|c|c|c|c|c|c|c|c|}
\hline Fiber * & $\begin{array}{l}\text { Cable Length (t) } \\
\text { from Jacket marks }\end{array}$ & $\begin{array}{c}A \text { to } B \text { loss / A ORL } \\
\mathrm{dBm} / \mathrm{dB}\end{array}$ & $\begin{array}{c}B \text { 10 A loss / } \mathrm{O} \text { ORL } \\
\mathrm{dBm} / \mathrm{dB}\end{array}$ & $\begin{array}{c}\text { Average loss } \\
\text { dobm }\end{array}$ & $\begin{array}{c}\text { Optical } \\
\text { Reterence } \\
\text { Levet (AB) } \\
\end{array}$ & $\begin{array}{c}\text { Calculated } \\
\text { Optical } \\
\text { Attenuation (dB) }\end{array}$ & $\begin{array}{c}\text { Predicted } \\
\text { Total } \\
\text { Attenuation (dB) }\end{array}$ \\
\hline 1 & & 1 & 1 & & & & \\
\hline 2 & & 1 & 1 & & & & \\
\hline 3 & & 1 & 1 & & & & \\
\hline 4 & & 1 & 1 & & & & \\
\hline Fiber \# & $\begin{array}{l}\text { Cable Length (tt) } \\
\text { from Jackel marks }\end{array}$ & 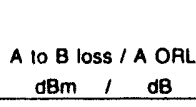 & $\begin{array}{c}B \text { to } A \text { loss / B OAL } \\
\begin{array}{c}\mathrm{dBm} \quad / \quad \mathrm{dB} \\
\end{array}\end{array}$ & $\begin{array}{c}\text { Average loss } \\
\quad \mathrm{dBm} \\
\end{array}$ & $\begin{array}{l}\text { Optical } \\
\text { Pelerence } \\
\text { Level (dB) }\end{array}$ & $\begin{array}{c}\text { Calculated } \\
\text { Optical } \\
\text { Altenuation (dB) }\end{array}$ & $\begin{array}{l}\text { Predicted } \\
\text { Total } \\
\text { Attenualion (dB) }\end{array}$ \\
\hline 1 & & 1 & 1 & & & & \\
\hline 2 & & 1 & 1 & & & & \\
\hline 3 & & 1 & 1 & & & & \\
\hline 4 & & 1 & 1 & & & & \\
\hline
\end{tabular}

Misc. Notes: 
Building Number -

Test Date -
From: IDR Name -

Outlet Box Number -
To: Room Number -

Outlet Type -

UTP CABLE

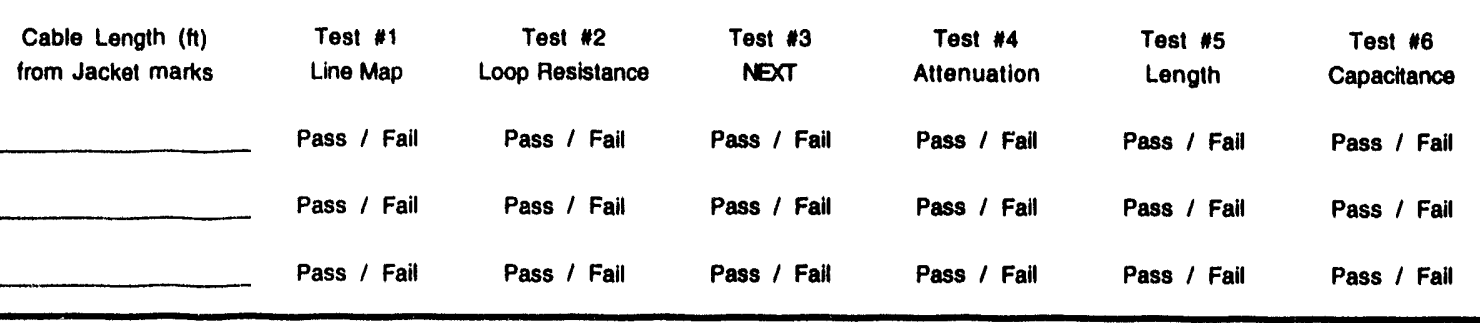

\section{OPTICAL FIBER CABLE}

Test Wavelength $=850 \mathrm{~nm}$

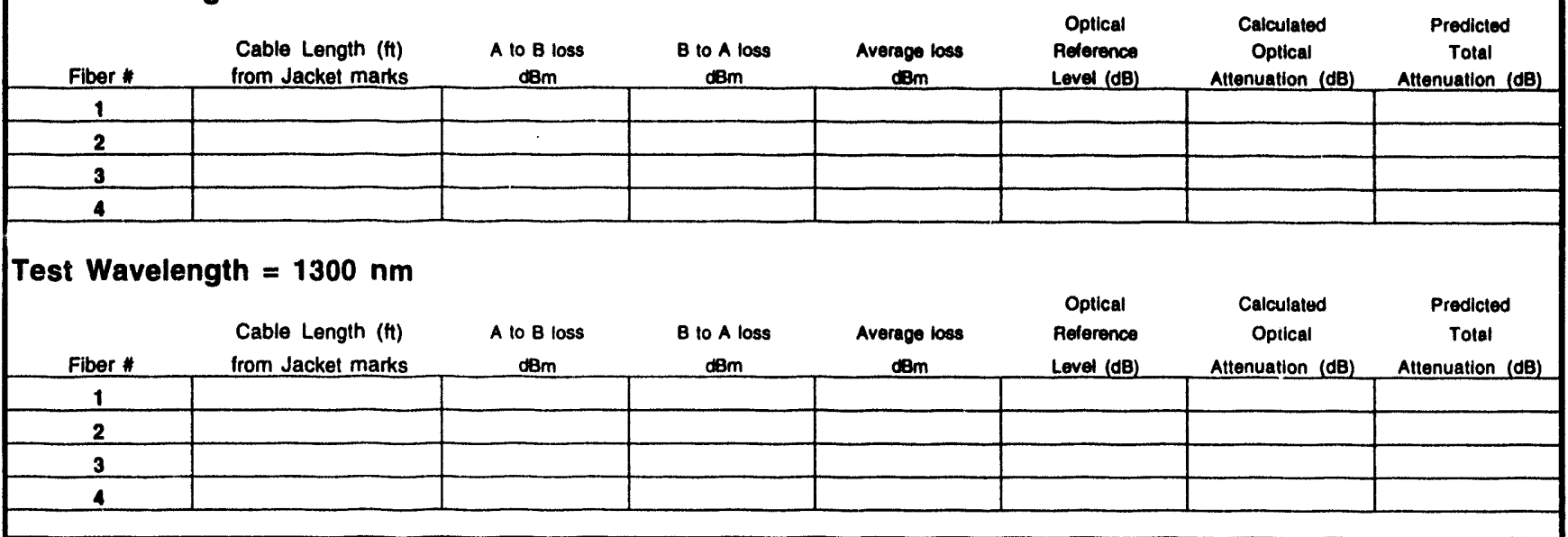

\section{SM OPTICAL FIBER CABLE}

Test Wavelength $=1310 \mathrm{~nm}$

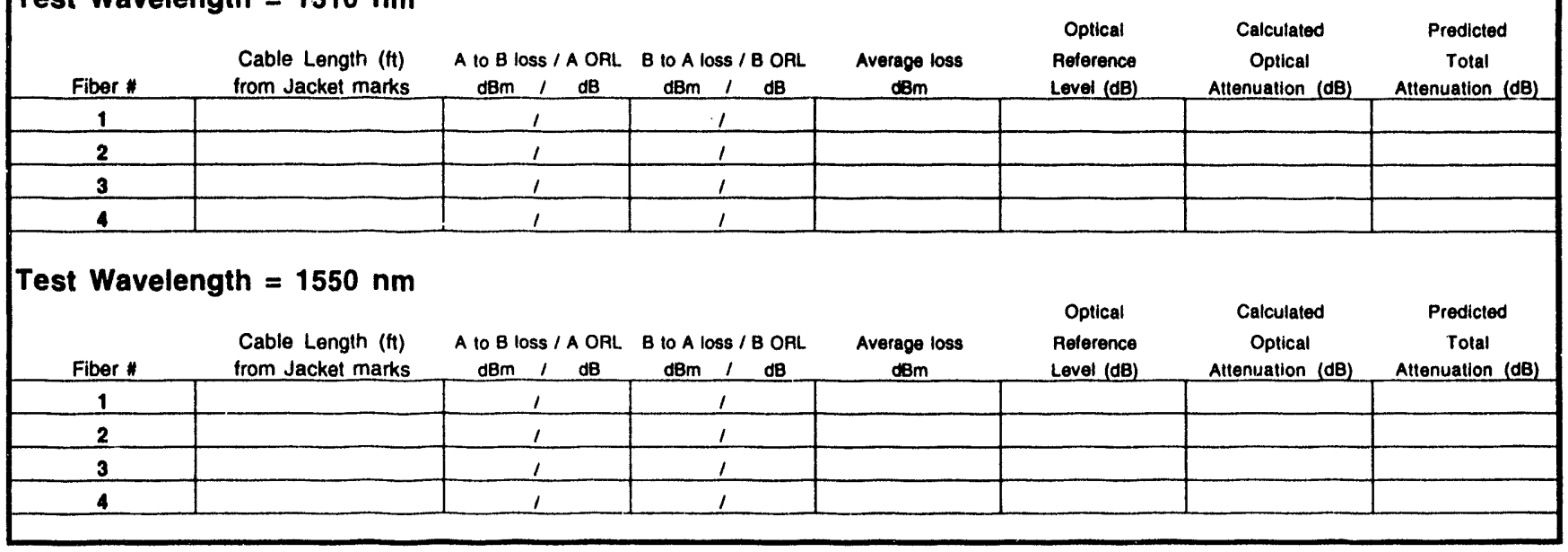

\section{Misc. Notes:}




\section{BLACK IDR-to-Outlet Cabling Form}

Bidg Number

\begin{tabular}{|c|c|c|c|c|c|c|c|}
\hline \multirow{2}{*}{$\begin{array}{l}\text { Box Number } \\
\text { Provided by } \\
1955-1\end{array}$} & \multirow{2}{*}{$\begin{array}{l}\text { Room Number } \\
\text { Provided by } \\
\text { Cable installer }\end{array}$} & \multicolumn{2}{|c|}{$\begin{array}{l}\text { Voice Frame Pairs } \\
\text { User Voice cable }\end{array}$} & \multicolumn{2}{|c|}{$\begin{array}{l}\text { Data Frame Pairs } \\
\text { User Data cable \#1 }\end{array}$} & \multicolumn{2}{|c|}{$\begin{array}{l}\text { Data Frame Pairs } \\
\text { User Data cable \#2 }\end{array}$} \\
\hline & & From & To & From & To & From & To \\
\hline & & 1 & 4 & 1 & 4 & 5 & 8 \\
\hline & & 5 & 8 & 9 & 12 & 13 & 16 \\
\hline & & 9 & 12 & 17 & 20 & 21 & 24 \\
\hline & & 13 & 16 & 26 & 29 & 30 & 33 \\
\hline & & 17 & 20 & 34 & 37 & 38 & 41 \\
\hline & & 21 & 24 & 42 & 45 & 46 & 49 \\
\hline & & 26 & 29 & 51 & 54 & 55 & 58 \\
\hline & & 30 & 33 & 59 & 62 & 33 & 66 \\
\hline & & 34 & 37 & 67 & 70 & 71 & 74 \\
\hline & & 38 & 41 & 76 & 79 & 80 & 83 \\
\hline & & 42 & 45 & 84 & 87 & 88 & 91 \\
\hline & & 46 & 49 & 92 & 95 & 96 & 99 \\
\hline & & 51 & 54 & 101 & 104 & 105 & 108 \\
\hline & & 55 & 58 & 109 & 112 & 113 & 116 \\
\hline & & 59 & 62 & 117 & 120 & 121 & 124 \\
\hline & & 63 & 66 & 126 & 129 & 130 & 133 \\
\hline & & 67 & 70 & 134 & 137 & 138 & 141 \\
\hline & & 71 & 74 & 142 & 145 & 146 & 149 \\
\hline & & 76 & 79 & 151 & 154 & 155 & 158 \\
\hline & & 80 & 83 & 159 & 162 & 163 & 166 \\
\hline & & 84 & 87 & 167 & 170 & 171 & 174 \\
\hline & & 88 & 91 & 176 & 179 & 180 & 183 \\
\hline & & 92 & 95 & 184 & 187 & 188 & 191 \\
\hline & & 96 & 99 & 192 & 195 & 196 & 199 \\
\hline & & 101 & 104 & 201 & 204 & 205 & 208 \\
\hline & & 105 & 108 & 209 & 212 & 213 & 216 \\
\hline & & 109 & 112 & 217 & 220 & 221 & 224 \\
\hline & & 113 & 116 & 226 & 229 & 230 & 233 \\
\hline & & 117 & 120 & 234 & 237 & 238 & 241 \\
\hline & & 121 & 124 & 242 & 245 & 246 & 249 \\
\hline & & 126 & 129 & 251 & 254 & 255 & 258 \\
\hline & & 130 & 133 & 259 & 262 & 263 & 266 \\
\hline & & 134 & 137 & 267 & 270 & 271 & 274 \\
\hline & & 138 & 141 & 276 & 279 & 280 & 283 \\
\hline & & 142 & 145 & 284 & 287 & 288 & 291 \\
\hline & & 146 & 149 & 292 & 295 & 296 & 299 \\
\hline
\end{tabular}

Office Outlet RJ45 positioning (left to right) Voice, Data 1, Data 2 Skip 25th pair position on each 110 row to keep cable pairs grouped
Voice Frame Pairs Voice cable 
Bldg Number

Provided by

1955-1
Box Number
Room Number

Provided by

Cable installer
Office Outlet RJ45 positioning (left to right) Voice, Data 1, Data 2 Skip 25th pair position on each 110 row to keep cable pairs grouped
Voice Frame Pairs

User Voice cable

\section{Data Frame Pairs \\ User Data cable \#1}

From To

\section{From To}

\section{Data Frame Pairs}

User Data cable \#2

\begin{tabular}{|c|c|c|c|c|c|c|c|}
\hline 1955.1 & Cable installer & From & To & From & To & From & To \\
\hline & & 151 & 154 & 301 & 304 & 305 & 308 \\
\hline & & 155 & 158 & 309 & 312 & 313 & 316 \\
\hline & & 159 & 162 & 317 & 320 & 321 & 324 \\
\hline & & 163 & 166 & 326 & 329 & 330 & 333 \\
\hline & & 167 & 170 & 334 & 337 & 338 & 341 \\
\hline & & 171 & 174 & 342 & 345 & 346 & 349 \\
\hline & & 176 & 179 & 351 & 354 & 355 & 358 \\
\hline & & 180 & 183 & 359 & 362 & 363 & 366 \\
\hline & & 184 & 187 & 367 & 370 & 371 & 374 \\
\hline & & 188 & 191 & 376 & 379 & 380 & 383 \\
\hline & & 192 & 195 & 384 & 387 & 388 & 391 \\
\hline & & 196 & 199 & 392 & 395 & 396 & 399 \\
\hline & & 201 & 204 & 401 & 404 & 405 & 408 \\
\hline & & 205 & 208 & 409 & 412 & 413 & 416 \\
\hline & & 209 & 212 & 417 & 420 & 421 & 424 \\
\hline & & 213 & 216 & 426 & 429 & 430 & 433 \\
\hline & & 217 & 220 & 434 & 437 & 438 & 441 \\
\hline & & 221 & 224 & 442 & 445 & 446 & 449 \\
\hline & & 226 & 229 & 451 & 454 & 455 & 458 \\
\hline & & 230 & 233 & 159 & 462 & 463 & 466 \\
\hline & & 234 & 237 & 467 & 470 & 471 & 474 \\
\hline & & 238 & 241 & 476 & 479 & 480 & 483 \\
\hline & & 242 & 245 & 484 & 487 & 488 & 491 \\
\hline & & 246 & 249 & 492 & 495 & 496 & 499 \\
\hline & & 251 & 254 & 501 & 504 & 505 & 508 \\
\hline & & 255 & 258 & 509 & 512 & 513 & 516 \\
\hline & & 259 & 262 & 517 & 520 & 521 & 524 \\
\hline & & 263 & 266 & 526 & 529 & 530 & 533 \\
\hline & & 267 & 270 & 534 & 537 & 538 & 541 \\
\hline & & 271 & 274 & 542 & 545 & 546 & 549 \\
\hline & & 276 & 279 & 551 & 554 & 555 & 558 \\
\hline & & 280 & 283 & 559 & 562 & 563 & 566 \\
\hline & & 284 & 287 & 567 & 570 & 571 & 574 \\
\hline & & 288 & $29 i$ & 576 & 579 & 580 & 583 \\
\hline & & 292 & 295 & 584 & 587 & 588 & 591 \\
\hline & & 296 & 299 & 592 & 595 & 596 & 599 \\
\hline
\end{tabular}




\section{RED IDR-to-Outlet Cabling Form}

Bldg Number

Box Number Room Number

Provided by

1955-1

Provided by

Cable installer
Office Outlet RJ45 positioning (left to right) Data 1, Data 2, Data 3 Skip 25th pair position on each 110 row to keep cable pairs grouped

\section{Data Frame Pairs}

User Data cable \#3 From To From To 


\section{RED IDR-to-Outlet Cabling Form}

Bldg Number

Box Number

Provided by

1955-1
Office Outlet RJ45 positioning (left to right) Data 1, Data 2, Data 3

Skip 25th pair position on each 110 row to keep cable pairs grouped

\begin{tabular}{|c|c|c|c|c|c|c|c|}
\hline \multicolumn{2}{c}{ Cable installer } & From & \multicolumn{1}{c}{ To } & From & To & From & To \\
\hline & & 301 & 304 & 305 & 308 & 309 & 312 \\
\hline & & 313 & 316 & 317 & 320 & 321 & 324 \\
\hline & & 326 & 329 & 330 & 333 & 334 & 337 \\
\hline & & 338 & 341 & 342 & 345 & 346 & 349 \\
\hline & & 351 & 354 & 355 & 358 & 359 & 362 \\
\hline & & 363 & 366 & 367 & 370 & 371 & 374 \\
\hline & & 376 & 379 & 380 & 383 & 384 & 387 \\
\hline & & 388 & 391 & 392 & 395 & 396 & 399 \\
\hline & & 401 & 404 & 405 & 408 & 409 & 412 \\
\hline & & 413 & 416 & 417 & 420 & 421 & 424 \\
\hline & & 426 & 429 & 430 & 433 & 434 & 437 \\
\hline & & 438 & 441 & 442 & 445 & 446 & 449 \\
\hline & & 451 & 454 & 455 & 458 & 459 & 462 \\
\hline & & 463 & 466 & 467 & 470 & 471 & 474 \\
\hline & & 476 & 479 & 480 & 483 & 484 & 487 \\
\hline & & 488 & 491 & 492 & 495 & 496 & 499 \\
\hline & & 501 & 504 & 505 & 508 & 509 & 512 \\
\hline & & 513 & 516 & 517 & 520 & 521 & 524 \\
\hline & & 526 & 529 & 530 & 533 & 534 & 537 \\
\hline & & 538 & 541 & 542 & 545 & 546 & 549 \\
\hline & & 551 & 554 & 555 & 558 & 559 & 562 \\
\hline & & 563 & 566 & 567 & 570 & 571 & 574 \\
\hline & & 576 & 579 & 580 & 583 & 584 & 587 \\
\hline & & 588 & 591 & 592 & 595 & 596 & 599 \\
\hline
\end{tabular}




\section{DISTRIBUTION}

\begin{tabular}{rll}
183 & MS0807 & R. L. Adams, 1955 \\
1 & MS9018 & $\begin{array}{l}\text { Central Technical Files, } \\
8523-2\end{array}$ \\
5 & MS0899 & Technical Library, 7141 \\
1 & MS0619 & $\begin{array}{l}\text { Technical Publications, 7151 } \\
\text { Document Processing } \\
\text { for DOE/OSTI, 7613-2 }\end{array}$ \\
\hline MS0100
\end{tabular}


$Y$
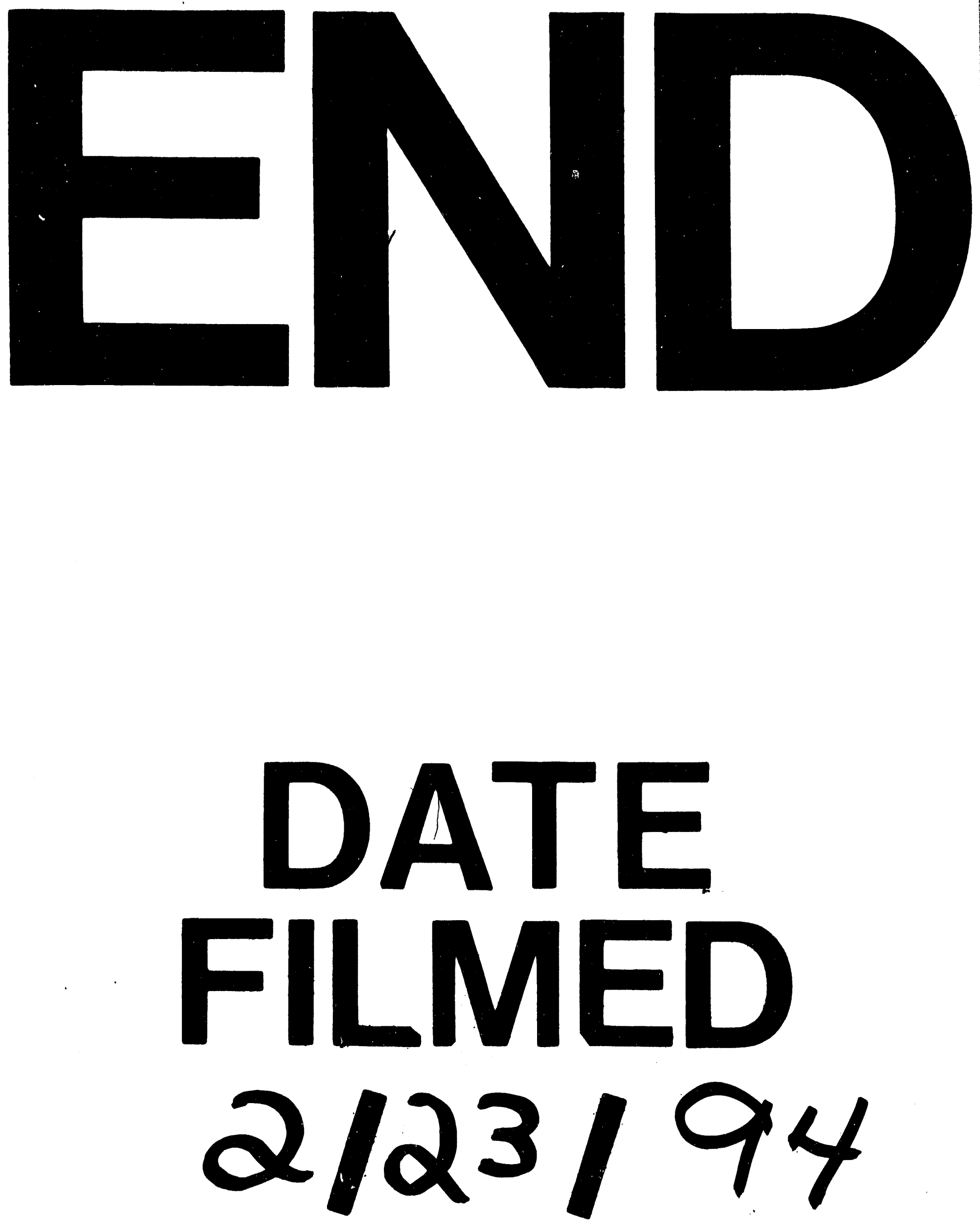

1 


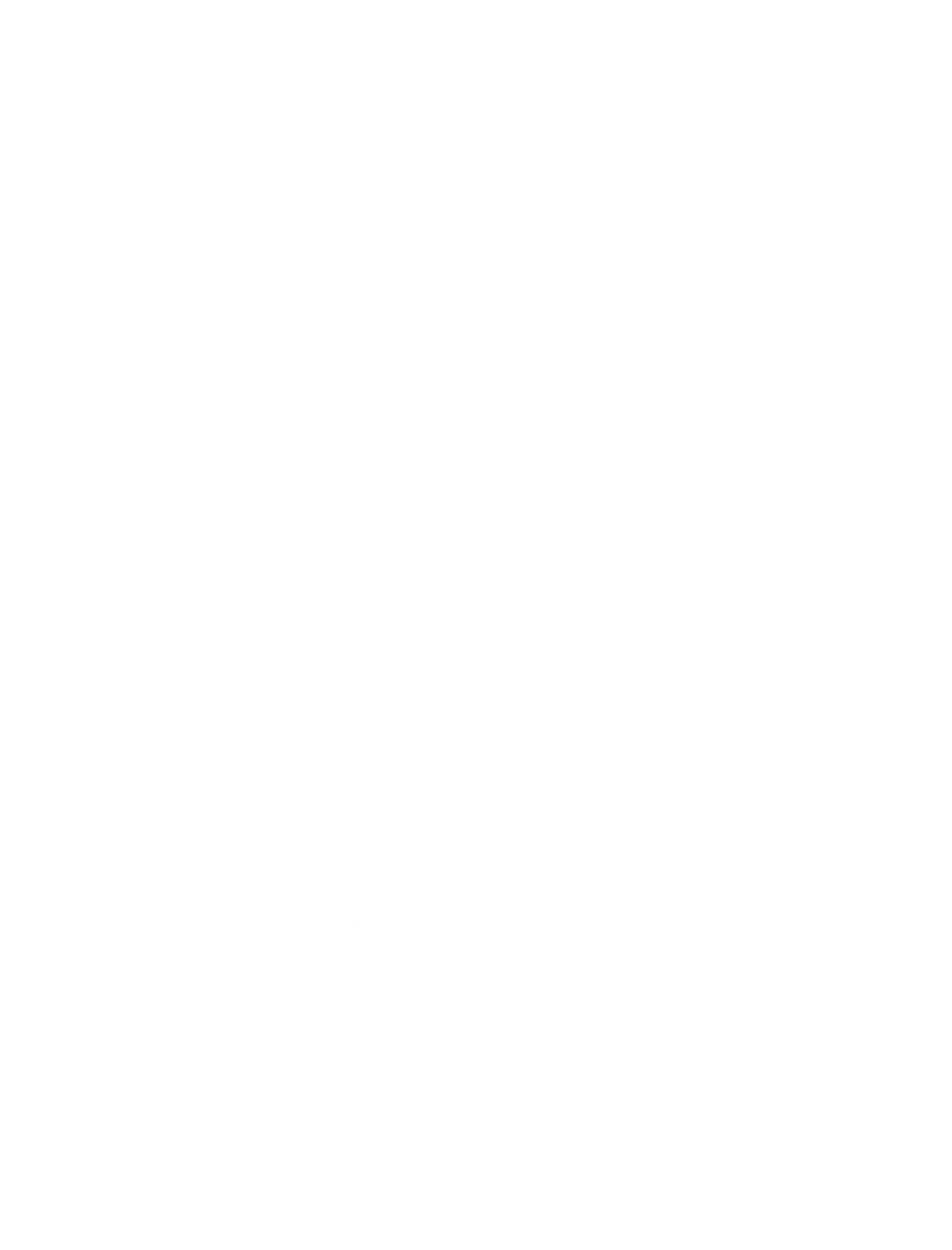

